\title{
Automation of enzyme assays
}

\author{
A. W. SKILLEN \\ From the Department of Clinical Biochemistry, Royal Victoria Infirmary, Newcastle upon Tyne
}

The increasing use of enzymes as aids to clinical diagnosis has made it mandatory for clinical biochemists to develop techniques and instrumentation to enable large numbers of specimens to be processed quickly with adequate accuracy. The main objective in enzyme assay is to determine the initial reaction rate, as it is only during this period that there is a linear relationship between the rate and enzyme concentration. There are four approaches to rate measurements which are given in Table I. In practice it is normal for most enzyme estimations to be made by the first and third of these, the fourth being only applicable to enzyme systems where changes in acid or base are to be monitored.

Schwartz and Bodansky (1963) have defined three stages of automation dependent upon the degree of automation of the assay procedure (Table II). Even with stage I automation there are means of work simplification which increase the capabilities of the technique. In the present discussion a variety of

\begin{tabular}{ll}
\hline Method & Procedure \\
\hline Constant-time & $\begin{array}{l}\text { The total change in signal measured over constant } \\
\text { time interval is determined }\end{array}$ \\
Variable-time & $\begin{array}{l}\text { The time required for the signal to change over a } \\
\text { fixed interval is determined }\end{array}$ \\
Slope & $\begin{array}{l}\text { The change in the signal response against time is } \\
\text { recorded }\end{array}$ \\
Signal-stat & $\begin{array}{l}\text { The amount of reagent necessary for maintaining } \\
\text { a constant signal is determined }\end{array}$ \\
\hline
\end{tabular}

Table I Methods for measurement of initial reaction rates (Pardue, 1968)

\begin{tabular}{ll}
\hline Stage I & $\begin{array}{l}\text { Manual preparation of reaction mixture; automatic } \\
\text { measurement and recording of enzyme activity }\end{array}$ \\
Stage II & $\begin{array}{l}\text { Automatic preparation of reaction mixture; auto- } \\
\text { matic measurement and recording of enzyme } \\
\text { activity }\end{array}$
\end{tabular}

Stage III As stage II with feedback control of instrumentation

Table II Automation of enzyme assays (Schwartz and Bodansky, 1963) systems will be described which can be classed as semi-automatic or fully automatic.

\section{Semi-automatic Techniques}

The basis of all these is the recording spectrophotometer or colorimeter. The enzyme substrate mixture is prepared, transferred to a spectrophotometer, and the change in optical density with time recorded (Fig. 1). The development of automatic cell changing accessories for spectrophotometers was the first big step forward in automatic enzyme analysis. These enable four to six samples to be measured simultaneously, the movement of the cuvette being programmed to suit the rate of reaction. When using this type of equipment, work-simplification procedures such as the use of autodilutors or syringe pipettes, and preliminary mixing of solutions can greatly speed the preparation of the reaction mixture.

The main drawback of a methodology of this type is the difficulty in initiating the reaction quickly and then determining the initial rate before it falls off. This is especially so when relatively fast reactions such as that of lactate dehydrogenase (EC 1.1.1.27) are to be measured. The best development in this field has been the Reaction Rate Analyser ${ }^{1}$ where the reaction is initiated automatically by the injection of substrate and the change in optical density at $340 \mathrm{~nm}$ monitored immediately (Fig. 2).

With this equipment serum samples are diluted with buffered coenzyme in disposable cuvettes. The cuvettes are placed in racks which are fed automatically through a thermostatted tunnel. After 15 minutes, when the contents of the cuvette have reached the correct incubation temperature, the following automatic procedure takes place: an appropriate volume of substrate is dispensed into each cuvette which is then stirred and the change in optical density recorded for a fixed time period (1-10 min). A most useful facility with this equipment is the automatic scale reduction: if the change in optical density (OD) reaches full scale deflection (OD 0.05) within the measuring period the instru'Obtainable from LKB Instruments Ltd., 232 Addington Road, Croydon, Surrey. 


\section{MANUAL SAMPLE PREPARATION}

\section{SPECTROPHOTOMETER}

\section{RECORDER}

Fig. 1 Simple stage 1 automation. The first step, ie, sample preparation and transfer to spectrophotometer, is manual.

\section{DIGITAL} PRINT-OUT
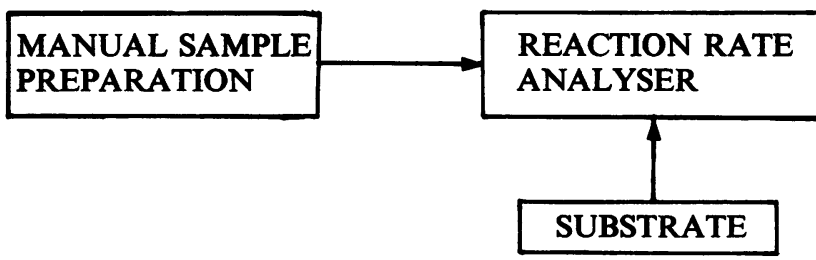

Fig. 2 Semi-automation with a reaction rate analyser.

Sample preparation is manual, but the reaction is initiated automatically.

ment automatically switches to a lower sensitivity (full scale OD 0.2). This instrument has proved simple to use with excellent reproducibility. At present it is suitable for any enzyme which can be estimated by monitoring optical density at $340 \mathrm{~nm}$. There is also

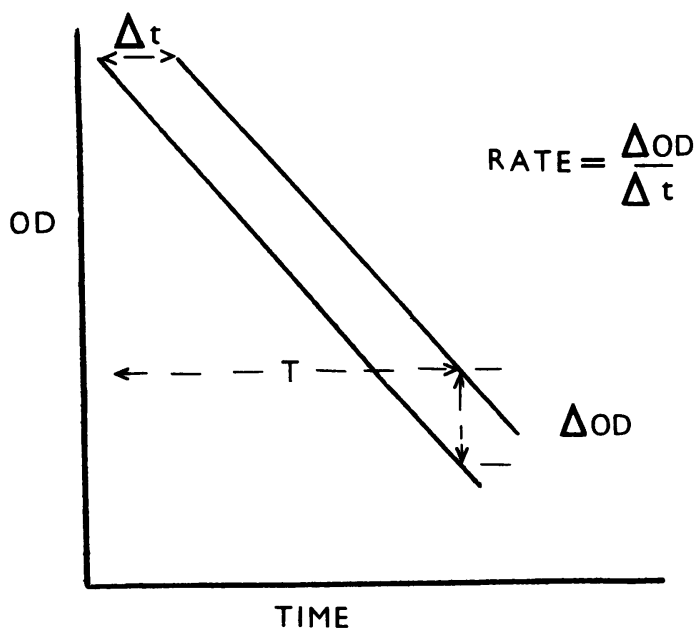

Fig. 3 Approach to automated determination of the reaction rate of Trayser and Seligson (1969). The reaction in each sample is initiated at times $t_{1}$ and $t_{2}$ the difference between them being $\Delta t$ which is relatively easy to determine. The difference in optical density $(\triangle O D)$ is affected only by $\Delta t$ and the activity of the enzyme. a $405 \mathrm{~nm}$ filter available for measuring alkaline pBos phatase with p-nitrophenyl phosphate as substigater

An excellent approach has been that of Tra⿳亠丷厂si and Seligson (1969) who have proposed a method i. which two identical mixtures of serum and buffered substrate are prepared, and the reaction of one $\frac{18}{85}$ initiated at a fixed time $(\Delta \mathrm{t})$ after the other (Fig. 3ी After a convenient incubation period the differenge in optical density ( $\triangle O D$ ) between the two samples is measured with a double-beam spectrophotometer. $\Delta \mathrm{OD} / \Delta \mathrm{t}$ is a measure of enzyme concentration. 岁 can normally be varied at will according to the valus of $\triangle O D$ required and if the extinction coefficient of the substance measured is known the change of optical density can be directly converted to $\mu$ moß, calibration with standard enzyme samples beirg unnecessary. It should not be difficult to produge instrumentation to automate the sample preparation and accurately reproduce $\Delta \mathrm{t}$. A commercials. available instrument using this technique is not yet on the market but the versatility of the methot should soon lead to such a development.

\section{Automated Techniques}

Fully automated enzyme assay has been developêd both with continuous flow and discrete systems. The majority of the former, of course, have been cons cerned with the Technicon AutoAnalyzer ${ }^{1}$ and ${ }^{1}$ Technicon Instruments Ltd, Hansworth Lane, Chertsey, Surrey. 
general use 'constant-time' techniques rather than the preferable 'slope' techniques.

\section{AUTOANALYZER TECHNIQUES (CONTINUOUS FLOW)}

These have been developed with colorimetric, spectrophotometric, and fluorometric measurement of the enzyme activity. The dangers of single point analysis have been emphasized by many workers but if care is taken to ensure that the calibration curve is nearly linear over the range of enzyme activities to be measured, these can largely be overcome. It is possible to dilute high activity serum to bring it into the linear part of the curve but this process may itself result in erroneous measurements, especially in the case of serum alkaline phosphatase (EC 3.1.3.1) (Nath and Ghosh, 1963). One of the main advantages of the AutoAnalyzer is that the enzyme reaction can be stopped after a fixed incubation period and the products directly mixed with, or dialysed into, a colour reagent. This latter method often obviates the need to measure serum 'blanks'.

An approach towards a two-point analysis using the AutoAnalyzer system was introduced by Pitot, Pries, Poirier, and Cutler (1966). In this technique the sample stream is split in two equal parts and one half incubated for a short period (eg, five minutes) and the other half for a longer period (eg, 15 minutes) (Fig. 4). After incubation the reaction is stopped and the short-incubation time stream passed through a time-delay coil (here 10 minutes) to synchronize the two streams which then pass through a dual-differential colorimeter where the long incubation-time stream is read against the short stream to give a direct measure of the enzyme activity.

Pitot and Pries (1964) had previously devised a system where the reaction mixture was transferred to the flow cell, the pump stopped, and the change in absorbance with time recorded. The pump was then restarted and the procedure repeated. It is debatable whether the Technicon pump can stand up to this stop-start procedure for very long.

In the near future Technicon are to introduce a completely new automatic enzyme analyser ${ }^{1}$ where the normal segmented sample-substrate stream is pumped at slow speed through an incubated glass coil. When the first portion of the sample reaches the end of this coil the pump is accelerated so that in effect a gradient is produced with last portion of the sample being incubated for only a very short time. The reaction mixture flows to the colorimeter and produces a trace corresponding to the incubation-

'Since this paper went to press Technicon have withdrawn this instrument.

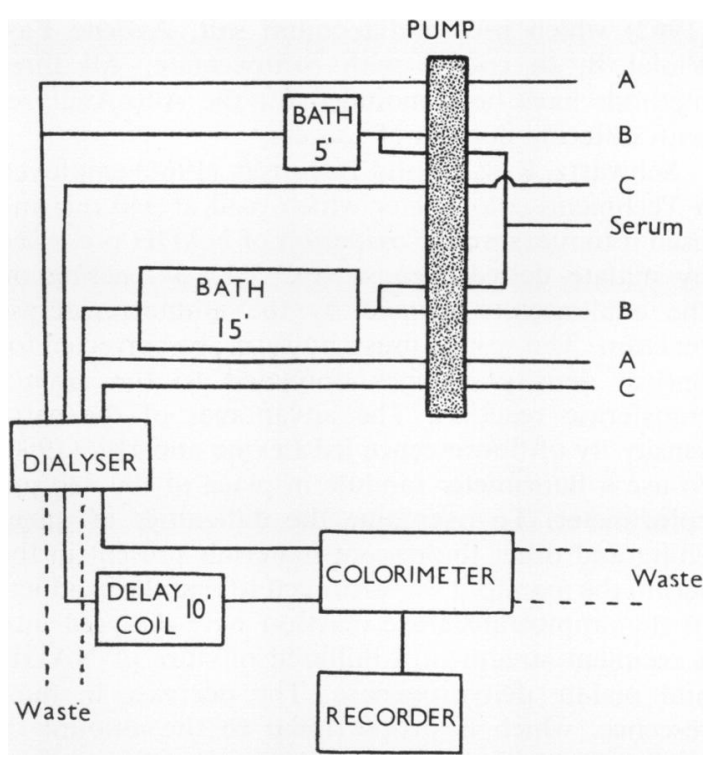

Fig. 4 Two-point assay with AutoAnalyzer with two parallel streams incubated for five and 15 minutes respectively. Serum is initially mixed with substrate $(B)$, and after incubation the reaction stopped with reagent $(A)$ and the mixture dialysed into reagent $(C)$. The differential colorimeter then gives a measure of enzyme activity over 10 minutes.

time gradient; this trace can be used to estimate the enzyme activity.

This last procedure does not do away with the most troublesome factor in AutoAnalyzer assays, namely, the need to run standards every day to check for variations in pumping speeds and flow rates. However, notwithstanding these disadvantages most workers find good correlation between the enzyme activity measured by manual and AutoAnalyzer techniques. As the latter play such a large part in most hospital laboratories the AutoAnalyzer methodology for the three serum enzymes most commonly estimated, viz, aspartate aminotransferase (EC 2.6.1.1.), lactate dehydrogenase and alkaline phosphatase will be discussed in detail.

\section{Aspartate aminotransferase}

There are three basic manual methods commonly used for the determination of this enzyme: first, the spectrophotometric method introduced by Karmen (1955) and its subsequent modifications; second, the colorimetric procedure depending on dinitrophenylhydrazine (Reitman and Frankel, 1957); third, the colorimetric procedure of Babson et al 
(1962) which uses a diazonium salt, Azoene Fast Violet B, to couple with oxaloacetate. All three methods have been modified for the AutoAnalyzer with differing degrees of success.

Schwartz, Kessler, and Bodansky (1961) employed a Technicon colorimeter which read at $340 \mathrm{~nm}$ and used it to measure the oxidation of NADH produced by malate dehydrogenase (EC 1.1.1.37) acting on the oxaloacetate formed by the aminotransferase reaction. The results must, however, be corrected for optical density changes unrelated to the aminotransferase reaction. The advantages of the extra sensitivity of fluorescence led Levine and Hill (1966) to use a fluorimeter module in place of the $340 \mathrm{~nm}$ colorimeter. To overcome the difficulties of quenching and other fluorescent materials present in the serum the manifold was arranged so that the products of the aminotransferase reaction were dialysed into a recipient stream of a buffered mixture of NADH and malate dehydrogenase. The decrease in fluorescence, which is proportional to the amount of oxaloacetate formed by the aminotransferase, was recorded.

Of the colorimetric procedures the type using a diazonium salt has been most successfully adapted for the AutoAnalyzer. Schaffert, Kingsley, and Getchell (1964) compared the automated dinitrophenylhydrazine technique with that using Azoene Fast Violet B and found that the specificity of the former was limited because the colour reagent reacted will all keto-groups; furthermore accurate results could be obtained only within a relatively small range. Scheidt, Nelson, and Levine (1966) and Morgenstern et al (1966) used Azoene Fast Violet B and Azoene Fast Red PDC respectively. The products of the aminotransferase reaction were dialysed into a buffer or water-recipient stream which was then mixed with a solution of the diazonium salt. The resultant dye was measured in a normal colorimeter, the amount of colour produced being directly proportional to the activity of the serum. Scheidt et al (1966) found that this type of technique gave results which correlated well with those of the manual spectrophotometric assay and showed that the dialysis step obviated the need for serum 'blanks', and hence doubled the analysis rate. This type of technique has been adopted for the SMA $12 / 30^{1}$. Moore and Sax (1969) have noted that certain sera showed much higher enzyme levels when measured by this system than by the spectrophotometric method. They traced this to the reaction of the diazonium salt with acetoacetate and found that there were a number of patients with elevated blood sugars or blood ureas with apparent serum

${ }^{1}$ Technicon Instruments Ltd. aminotransferase levels of the order of the uppe limit of the normal range even when the enzyme was assayed without the substrate. It was also shown that blank corrections significantly reduced the apparent aminotransferase activity bringing $18 \%$ of abnorm震 aspartate aminotransferases into the normal range This emphasizes the dangers of colorimetric prof cedures and also the need to be wary of abnorma aspartate aminotransferase levels as shown b procedures which do not incorporate blanks especially in patients with diabetes.

\section{Lactate dehydrogenase}

Automated assay of this enzyme is commonly basegp on manual spectrophotometric methods rather tha the colorimetric ones which are subject to man of the same difficulties found with the amino transferase methods. The first AutoAnalyzer assat for this enzyme was described by Schwartz and his coworkers (1961) who used the $340 \mathrm{~nm}$ colorimeter to measure the oxidation of NADH produced by the enzyme. A modification of this system, in which the reaction was stopped by the addition of sodium hydroxide before the NADH level was measured was introduced by Strandjord and Clayson (1964)

A new technique in which the whole AutoAnalyzef channel is installed in a thermostatted box has bee⿰习习 devised by Berry and Wallis (1966). Serum dilutions are placed in the sampler cups, and immediate before aspiration an aliquot of pyruvate is injecter into each cup and stirred with a vibrating padd $\overrightarrow{0}$ The enzyme-substrate mixture is pumped to the 340 $\mathrm{nm}$ colorimeter, the first portion of the samp娄 arriving one minute after aspiration begins. The passage of the reaction mixture from each sample through the flow cell takes two minutes and resuls in a characteristic recorder trace with a linear rate of fall of optical density with time.

Fluorometric determination of NADH was used by Brooks and Olken (1964) who used the 'forwarg lactate to pyruvate reaction which gave excellent correlation with the manual spectrophotometris assay. Morgenstern, Flor, Kessler, and Klein (1965) used a copper-neocupreine solution as a colour reagent for NADH and Hochella and Weinhouste (1965) used reduced NAD dehydrogenase (EE. 1.6.99.3) and p-iodonitrotetrazolium Violet(INT) fos the same purpose. Babson and Arndt (1970) hays recently pointed out the presence of LD-inhibito in NAD, and suggest that as colorimetric procedures employing phenazine methosulphate as an inter mediate electron acceptor use much less NAD thi the corresponding spectrophotometric assay, the are less affected by these inhibitors. Both groups used the 'forward' reaction and the latter method? ology has been adopted for use with the SMA 12/6 
Of all these techniques, only that of Berry and Wallis (1967) can be said to approach the preferable 'slope' type and thus indicate whether or not zeroorder kinetics are being followed.

\section{Alkaline phosphatase}

Automated assay of this enzyme depends on the use of either phenyl phosphate or p-nitrophenyl phosphate as substrate. With the former substrate aminoantipyrine and ferricyanide are used as colour reagents (Marsh, Fingerhut, and Kirsch, 1959). The serum is mixed with buffered substrate, incubated, mixed with colour reagent, and the optical density measured in a colorimeter. The serum samples have either to be run again in the absence of substrate or a dual channel system with a differential colorimeter employed to give serum 'blanks'. The use of $p$ nitrophenyl phosphate as a substrate in an automated technique was developed by Morgenstern et al (1965), the p-nitrophenol produced by the action of the enzyme being dialysed into a recipient stream of 2-amino-2-methyl-1-propanol before colorimetry at $410 \mathrm{~nm}$. This dialysis step is said to eliminate the need for a blank correction.

An interesting, though complicated procedure, for reaction rate measurement of serum alkaline phosphatase activity has been developed by Brown and Ebner (1967) who made preliminary dilutions of serum with buffered substrate and placed these in a sampler plate modified so that the sample cups could be kept at $37^{\circ} \mathrm{C}$. Each serum dilution was reaspirated after 15 and 30 minutes. This procedure results in each sample giving at least two points on the reaction rate curve thus indicating whether the kinetics are zero order and making the measurement of serum blanks unnecessary. It does, however, involve the time-consuming manual preparation of the serum dilutions.

Cornish, Neale, and Posen (1970) have developed a fluorometric assay with 4-methylumbelliferyl phosphate as substrate. This assay is apparently so sensitive that normal adult serum has to be diluted 1 in 50 before assay; the results compare well with those obtained with the conventional assay using phenyl phosphate as substrate.

\section{DISCRETE ANALYSERS}

A number of fully automatic enzyme analysers have recently become available or are soon to be on the market. These of course include the complete analysis systems such as the Autochemist ${ }^{1}$, Robot Chemist ${ }^{2}$, DSA-560 ${ }^{3}$, and Centrifichem ${ }^{4}$ analyzers. Specific enzyme analysers such as the Enzymat ${ }^{5}$ and the Zymat $^{6}$ are also in production (Fig. 5). The Enzymat is based on the Mecolab system with a Roboscan attachment. The buffered substrate serum dilutions are transferred to a cuvette in a 15-place turret. The optical densities of these cuvettes are recorded consecutively and repeatedly, and in this way reaction rate curves can be drawn. The apparatus is, however, rather cumbersome. The Zymat, soon to be reintroduced into the United Kingdom market, has been specifically designed for assay of those enzymes which can be monitored at $340 \mathrm{~nm}$. It has two concentric wheels, one for the serum samples and one for the reaction cuvettes, which advance together once every two minutes. The instrument is programmed to pick up a serum sample, dilute it with the appropriate buffered substrate, transfer it to the cuvette, incubate the mixture, inject a reagent to trigger off the enzyme reaction, stir with an air jet, and move the cuvette into the light path. The reaction rate is monitored and produced as a digital printout.

The Unicam AC60/61 system ${ }^{7}$ is also an effective means of enzyme analysis and as it may be coupled up to a conventional spectrophotometer is more versatile than the Zymat. It is, however, not very good for fast reactions, having a 60 -second delay between starting the reaction and monitoring the optical density of the solution. It also requires at least $3 \mathrm{ml}$ of reaction mixture whereas many other analysers now operate on a minimum of $1 \mathrm{ml}$.

1AGA Medical Division, Lidingo 1, Sweden.

'Warner-Chilcott, Richmond, Calif., USA.

'Beckman Ltd, Sunley House, Bedford Park, Croydon.

Union Carbide Corp., Tarrytown, New York.

sJoyce-Loebl and Co Ltd, Princes Way, Team Valley, Gateshead.

'Bausch and Lomb Inc., Rochester, N.Y., USA.

'Pye Unicam Ltd, York St, Cambridge.

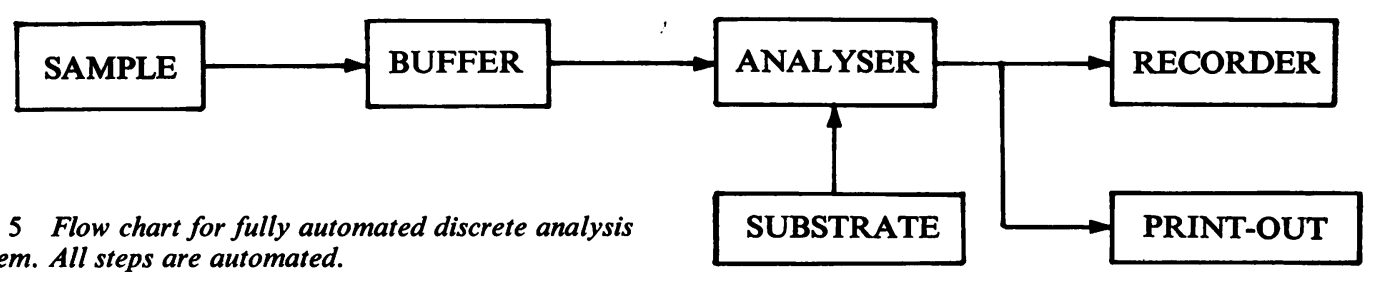

Fig. 5 Flow chart for fully automated discrete analysis system. All steps are automated. 
DATA ACQUISITION AND STAGEIII AUTOMATION Most semi-automated or discrete automated systems and some continuous flow techniques provide a recorder trace showing the change in optical density with time, ie, plots voltage output of photometer against time. It is possible by use of an analogdigital convertor and associated process units to measure $d v / d t$ and print this out directly in enzyme units together with the percentage deviation from linearity of the reaction rate slope. This type of equipment is soon to be available for the LKB analyser.

Toren, Eggert, Sherry, and Hicks (1970) have described an instrument for interfacing any recording spectrophotometer to a clinical laboratory computer where the rate signal is sampled and transmitted to the computer which prints out the result in enzyme units with comments on nonlinearity, drift, and quality control. Roodyn (1970) has recently developed a generalized system for the automation of enzyme assays in which an AutoAnalyzer is computer controlled whereby it is possible to regulate flow rate, temperature, and many other parameters, thus making possible the stage III automation originally proposed by Schwartz and Bodansky (1963).

\section{Summary}

Automation of enzyme assays is becoming increasingly important and instrumentation is being developed to satisfy this need. Reaction rate analysers which use the preferable 'slope' techniques rather than the less satisfactory 'constant-time' or 'singlepoint' analyses are becoming more widespread.

The stage I systems at present available are: recording spectrophotometers with autodilutors for sample preparation and the Reaction Rate Analyser

The stage II systems available are the AutoAnalyzer, and the Zymat 340, Enzymat, and AC60/61.

Data acquisition units can give direct printout in enzyme units from all systems and computer control of stage II systems is under development.

\section{References}

Babson, A. L., and Arndt, E. G. (1970). Lactic dehydrogenase inhibitors in NAD. Clin. Chem., 16, 254, 255.

Berry, M. N., and Walli, A. K. (1967). The automated assay of serum lactate dehydrogenase activity. In Automation in Analytical Chemistry, pp. 389-393. Mediad Press, New York.

Brooks, L., and Olken, H. G. (1965). An automated fluorometric method for determination of lactic dehydrogenase in serum. Clin. Chem., 11, 748-762.
Brown, H. H., and Ebner, M. R. (1967). Reaction rate measurement multiple enzyme samples by continuous flow analysis. $C$ lis. Chem., 13, 847-854.

Cornish, C. J., Neale, F. C., and Posen, S. (1970). An automated fluorometric alkaline phosphatase microassay with 4-methȳumbelliferyl phosphate as a substrate. Amer. J. clin. Path., \$; 68-67.

Hochella, N. J., and Weinhouse, S. (1966). Automated assay of lact dehydrogenase in urine. In Automation in Analytical Chemist pp. 539-544. Mediad Press, New York.

Karmen, A. (1955). A note on the spectrophotometric assay glutamic-oxalacetic transaminase in human blood serue. J. clin. Invest., 34, 131-133.

Levine, J. B., and Hill, J. B. (1966). Automated fluorometric determination of serum glutamic oxalacetic transaminase and serúm glutamic pyruvic transaminase. In Automation in Analyticti Chemistry, pp. 569-574, Mediad Press, New York.

Marsh, W. H., Fingerhut, B., and Kirsch, E. (1959). The adaptation of an alkaline phosphatase method for automatic colorimetfix analysis. Clin. Chem., 5, 119-126.

Moore, J. J., and Sax, S. M. (1969). Serum glutamic oxalacenc transaminase assay using the sequential multiple analyser (SMA 12/30). Clin. Chem., 15, 730-736.

Morgenstern, S., Oklander, M., Auerbach, J., Kaufman, J., and Klein, B. (1966). Automated determination of serum glutamic oxaloacetic transaminase. Clin. Chem., 12, 95-111.

Morgenstern, S., Flor, R., Kessler, G., and Klein, B. (1965). Aufumated determination of NAD-coupled enzymes. Determinatign of lactic dehydrogenase. Analyt. Biochem., 13, 149-161.

Morgenstern, S., Kessler, G., Auerbach, J., Flor, R. V., and Klein, $\mathbf{R}$. (1966). An automated p-nitrophenylphosphate serum alkaline phosphatase procedure for the AutoAnalyser. Clin. Chem., 쓱, 876-888.

Nath, R. L., and Ghosh, N. K. (1963). Studies on serum phosphatases II. Increase in active sites of serum alkaline phosphatase dilution. Enzymologia, 25, 350-358.

Pardue, H. L. (1968). Applications of kinetics to automated quan $\vec{Q}$ tative analysis. In Advances in Analytical Chemistris Instrumentation, vol. 7, pp. 141-207. Interscience, New Yetk:

Pitot, H. C., and Pries, N. (1964). The automated assay of complete enzyme reaction rates 1 . Methods and results. Analyt. Biode? 9, 454-466.

Pitot, H. C., Pries, N., Poirier, M., and Cutler, A. (1966). analysis of enzyme reactions by continuous and interruped flow procedure. In Automation in Analytical Chemist कि. pp. 555-558. Mediad Press, New York.

Reitman, S., and Frankel, S. (1957). A colorimetric method for determination of serum glutamic oxalacetic and glutarc pyruvic transaminases. Amer. J. clin. Path., 28, 56-63.

Roodyn, D. B. (1970). A generalised system for automation of enzyme assays. Biochem. J., 119, 823-837.

Schaffert, R. R., Kingsley, G. R., and Getchell, G. (1964). Automared determination of serum glutamic oxalacetic and glutamic pyruvic transaminase. Clin. Chem., 10, 519-532.

Scheidt, R. A., Nelson, V. A., and Levine, J. B. (1966). Automated determination of serum glutamic oxalacetic transaminase. In Automation in Analytical Chemistry, pp. 563-568. Medrad Press, New York.

Schwartz, M. K., and Bodansky, O. (1963). Automated methods oㅏ determination of enzyme activity. In Methods of Biochemreal Analysis, vol. 11, edited by D. Glick, pp. 211-246. Interscien@e, New York.

Schwartz, M. K., Kessler, G., and Bodansky, O. (1961). Automared assay of activities of enzymes involving the diphosphopyricine nucleotide-reduced diphosphopyridine nucleotide reaction. J. biol. Chem., 236, 1207-1211.

Strandjord, P. E., and Clayson, K. J. (1964). An automatic method for the determination of serum lactate dehydrogenase. CNith Chem., 10, 635.

Toren, E. C., Eggert, A. A., Sherry, A. E., and Hicks, G. P. (19 (b). Interfase instrumentation between computer and spectophotometer for reaction rate measurements. Clin. Chem., 46 , 215-221.

Trayser, K. A., and Seligson, D. (1969). A new 'kinetic' method for enzyme analysis suitable for automation. Clin. Chem., 15, 459. 